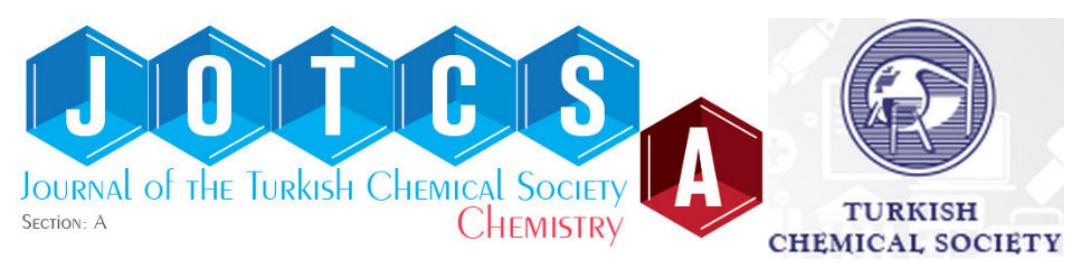

\title{
Synthesis of Novel Diarylethenes Bearing Naphthalimide Moiety and Photochromic Fluorescence Behaviors
}

\author{
Ersin ORHAN ${ }^{1 *}$ \\ ${ }^{1}$ Department of Chemistry, Faculty of Arts and Science, Düzce University, 81620 Düzce, \\ Turkey
}

\begin{abstract}
The objective of the research was to synthesize new photo-switchable photochromic fluorescence compounds. Starting from N-butyl-4-bromo-3-iodo-1,8naphthalimide, new compounds, namely 3,4-bis(2-phenyl-5-methyl-4-thiazolyl)-N-butyl1,8-naphthalimide 10 and 3,4-bis(3,5-dimethyl-4-isoxazolyl)-N-butyl-1,8-naphthalimide 20 were prepared via two-step Suzuki coupling reaction of aryl boronic acid and esters, and their photochromic fluorescence properties were investigated. Although all prepared bisaryl naphthylimides fluoresce due to the naphthylimide moiety, among them photochrome $\mathbf{1 0}$ displayed photochromism. On exposure to ultraviolet light, the photochrome $\mathbf{1 0}$ showed a pale yellow to blue-green color change due to the formation of ring closed form 1C, which reversed to the ring opened form $\mathbf{1 0}$ on exposure to visible light. Conversion ratio and quantum efficiency (from $O$ to $C$ form) for $\mathbf{1 0}$ were also determined. Additionally, a solvent effect on the fluorescence properties of $\mathbf{1 0}$ and $\mathbf{2 0}$ was investigated. Increase of solvent polarity results in a red shift (to longer wavelengths) of the fluorescence emissions.
\end{abstract}

Keywords: Photochromism; fluorescence; diarylethene; naphthalimide; solvent effect.

Cite this: Orhan E. Synthesis of Novel Diarylethenes Bearing Naphthalimide Moiety and Photochromic Fluorescence Behaviors. JOTCSA. 2017;4(2):25-40.

Submitted: March 05, 2017. Revised: March 14, 2017. Accepted: March 18, 2017.

DOI: $10.18596 /$ jotcsa.296370.

${ }^{*}$ Corresponding author. E-mail: ersinorhan@duzce.edu.tr Tel.: +90 3805412404 (internal 3959); Fax: +90 3805412403. 


\section{INTRODUCTION}

Photochromism is defined as a reversible change of the chemical on irradiation with the relevant light wavelength. Color change is caused by a two sided isomerization of the molecule (1). Photochromic organic molecules have attracted considerable interest due to their potential applications in optical memory and molecular systems; diarylethers are one of the most promising organic photochromic molecules because of their fatigue resistance and high thermal stability. Photochromic compounds have attracted to these applications because of their significant fatigue resistance and high reactivity in the solid state due to the thermal stability of the respective isomers. The photochromic compounds change not only the absorption spectrum but also the geometric and electronic structures in a reversible manner. Changes in molecular structure cause changes in physical properties of molecules such as fluorescence, electrical conductivity, magnetism, refractive index, and polarizability. In particular, the fluorescence modulation associated with the isomerization of diarylethylenes is seen as a promising means of obtaining non-destructive reading and safety records $(2-8,22)$.

Recently, a lot of research on photochromism has focused on the synthesis of new photochromic devices with modified central ethenes of diarylethylenes. Some examples of recently published novel photochromic compounds synthesized by this approach are as follows: bisarylthiazoles, bisarylthiophenes, naphthalimide derivatives, bisarylindenone derivatives, bisarylbenzindenone derivatives, bisaryl cyclopentenones, bisarylnaphthoquinones and the like (9-14).

Photochromic diarylethines have received great interest both in terms of both basic and practical perspectives. Although photochromic diaryl ethers have been extensively investigated for their application as optoelectronic devices based on changes in magnetic properties, electrochemical behavior, and chemical reaction, the main applications of photochromic diarylethenes are based on two methods: Producing transitions between two isomers different from their natural abilities; and the other is to perform a fluorescent diarylethene with a UV-Vis light source, showing the on/off fluorescent transition between the two isomers. External effect stimuli are usually sound, light, electrical, and mechanical power, and the light control mode among them is the easiest compared to other stimuli. Photochromic fluorescence diarylethers can be used to fabricate many light-sensitive materials. The diarylethenes can be considered promising because of their advantages such as two alternating photochromism, rapid reaction, high quantum yield, fatigue resistance, large variations in the absorption wavelength between the two isomers (1519). 
Multifunctional fluorescent molecules that combine diarylethene units have been examined for their intended applications in optical memory. If the chromophore's fluorescence matches the absorption of the near isomer of diarylethene, ultra-high density storage may be achieved by combining solid state fluorescence of solid emitters and photochromism of diarylethene. Some other chromophores, such as tetrafluoroethylene, naphthalimide, can be converted to diarylethene-like derivatives to obtain high contrast fluorescent keys (2023).

Recent developments in the design of diarylethene derivatives have allowed the central bridge unit to be flexibly selected. In this context, a heteroaryl ring is provided as the central bridging unit of diarylethenes to form photochromic naphthalimide derivatives (11, 19, 24-25).

So, our aim in this study is to synthesize a number of new diarylethene type photochromic fluorescence compounds that contains bisaryl naphthalimide moieties utilizing the Suzuki coupling reaction.

\section{EXPERIMENTAL}

\section{Materials and methods}

Materials

4-Bromo-1,8-naphthalic anhydride, 3,5-Dimethylisoxazole-4-boronic acid pinacol ester and other starting chemical compounds were purchased from the company Merck, SigmaAldrich, Acros Organics, and ABCR. 4-Bromo-N-butyl-3-iodo-1,8-naphthalimide (1) (11) and (5-methyl-2-phenylthiazole-4-yl)boronic acid (2) were prepared according to the procedures in the literature [26].

\section{Methods}

Some parts of solvent were of analytical grade and purified by distillation before use. Other reagents were used as received without further purification. Some part of studies of naphthalimide derivatives were performed under argon using standard schlenk techniques and dry solvents. All chemicals were purchased from Merck, Acros Organics, ABCR and Aldrich Chemical Company. ${ }^{1} \mathrm{H}$ and ${ }^{13} \mathrm{C}$ NMR spectra were recorded on Bruker $400 \mathrm{MHz}$ spectrometers for samples in $\left(\mathrm{CD}_{3}\right)_{2} \mathrm{SO}$ or $\mathrm{CDCl}_{3}$. The signals are expressed as parts per million downfield from tetramethylsilane, used as an internal standard ( $\delta$ value). Splitting patterns are indicated as $s$, singlet; $d$, doublet; $t$, triplet; q, quartet; m, multiplet. Mass spectra were recorded with an AB Sciex 4000 QTRAP LC-MS/MS. FT-IR spectra were measured using a SHIMADZU FT-IR spectrometer. Luminescence spectra were measured 
on a SHIMADZU RF-5301PC fluorescence spectrophotometer. UV-Vis spectra were recorded on a T80+ UV-VIS spectrophotometer. Photochemical reactions in organic solvents were carried out in a $10 \mathrm{~mm}$ path length quartz cell using an $8 \mathrm{~W}$ Three-Way UV lamp (Cole-Parmer) (for 365 nm) and an Obelux CR9 Forensic Lights Green (for $530 \mathrm{~nm}$ ). During the photoreaction, solutions in the cell were stirred. Melting points were measured in open capillary tubes with a Thermo Scientific 9200 melting point apparatus and are not corrected. Solvents were dried over anhydrous sodium sulfate. Flash column chromatographic separation was carried out on Merck Kieselgel 60 (230-400 mesh) using ethyl acetate and hexane as the eluent. Analytical thin-layer chromatography was performed on Merck pre-coated silica gel 60 F-254, 0.25-mm thick TLC plates.

\section{Synthesis}

3,4-Bis(2-phenyl-5-methylthiazole-4-yl)- N-butyl-1,8-naphthalimide (10) 3-(2-phenyl-5- methyl-4-thiazole-4-yl)-4-bromo-N-butyl-1,8-naphthalimide $(0.08 \mathrm{~g}, 0.15$ mmol), 2-phenyl-5-methyl-4-thiazolyl boronic acid $(0.10 \mathrm{~g}, 0.46 \mathrm{mmol})$ (2), potassium carbonate $(0.20 \mathrm{~g}, 1.5 \mathrm{mmol})$, tetrakis(triphenylphosphine)palladium(0) $(0.017 \mathrm{~g}, 0.015$ $\mathrm{mmol}$ ), and a catalytic quantity of tris(dibenzylideneacetone) dipalladium( 0 ) in tetrahydrofuran $(15 \mathrm{~mL})$ and water $(3 \mathrm{~mL})$ were stirred for $2 \mathrm{~h}$ at $45-50{ }^{\circ} \mathrm{C}$, and then mixture of solution was boiled for $3 \mathrm{~h}$. The reaction was followed by TLC. The reaction mixture was quenched with aqueous $\% 10 \mathrm{NaHCO}_{3}$ solution and extracted with ethyl acetate. The organic phase was washed with saturated $\mathrm{NaCl}$ solution, dried with anhydrous $\mathrm{MgSO}_{4}$, and the desiccant agent was filtered. Then the solvent was evaporated on a rotary evaporator. Raw product was purified by column chromatography over silica gel with ethyl acetate/n-hexane. 10 yellowish solid. Yield $0.04 \mathrm{~g}(41 \%)$ m.p.: $212-214{ }^{\circ} \mathrm{C}$. ${ }^{1} \mathrm{H}$ NMR (400 $\left.\mathrm{MHz}, \mathrm{CDCl}_{3}, \mathrm{ppm}\right): \delta 0.85\left(\mathrm{t}, 3 \mathrm{H},-\mathrm{CH}_{2} \mathbf{C H}_{3}\right), 1.27-1.41\left(\mathrm{~m}, 2 \mathrm{H},-\mathbf{C H}_{2} \mathrm{CH}_{3}\right), 1.58-1.70(\mathrm{~m}$, $\left.2 \mathrm{H},-\mathrm{NCH}_{2} \mathbf{C H}_{2}-\right), 2.34\left(\mathrm{~s}, 3 \mathrm{H},-\mathrm{CH}_{3}\right.$, thiazole), $2.38\left(\mathrm{~s}, 3 \mathrm{H},-\mathrm{CH}_{3}\right.$, thiazole), $4.12(\mathrm{t}, 2 \mathrm{H},-$ $\left.\mathrm{NCH}_{2}-\right), 7.73(\mathrm{t}, 1 \mathrm{H}$, naphthalene-H) $7.60(\mathrm{~s}, 1 \mathrm{H}$, naphthalene-H), 7.20-7.69 (m, 3H, phenyl- $\mathrm{H}), 7.80\left(\mathrm{~d}, 2 \mathrm{H},{ }^{3} \mathrm{~J}_{\mathrm{H}-\mathrm{H}}=6.8 \mathrm{~Hz}\right.$, phenyl-H), 8.55-8.65 $(\mathrm{m}, 2 \mathrm{H}$, naphthalene- $\mathrm{H}) .{ }^{13} \mathrm{C}$ NMR $\left(100 \mathrm{MHz}, \mathrm{CDCl}_{3}, \mathrm{ppm}\right): \delta=11.10\left(\mathrm{CH}_{3}\right), 12.91\left(\mathrm{CH}_{3}\right), 19.22\left(\mathrm{CH}_{3}\right), 28.64\left(\mathrm{CH}_{2}\right)$, $29.33\left(\mathrm{CH}_{2}\right), 39.15\left(\mathrm{~N}-\mathrm{CH}_{2}\right), 119.83\left(\mathrm{CPh}_{\mathrm{Ph}}\right), 121.43\left(\mathrm{C}_{\mathrm{Ph}}\right), 124.09\left(\mathrm{C}_{\mathrm{Ph}}\right), 124.72\left(\mathrm{C}_{\mathrm{Ph}}\right), 125.65$ $\left(\mathrm{C}_{\mathrm{ph}}\right), 126.14\left(\mathrm{C}_{\mathrm{Ph}}\right), 126.58\left(\mathrm{C}_{\mathrm{ph}}\right), 126.91\left(\mathrm{C}_{\mathrm{ph}}\right), 127.36\left(\mathrm{C}_{\mathrm{ph}}\right), 127.62\left(\mathrm{C}_{\mathrm{ph}}\right), 128.27$ ( $\mathrm{Cph}_{\mathrm{ph}}$,


( $\left.C_{\text {thiazole }}\right), 130.49$ (C $\left.C_{\text {thiazole }}\right), 131.21$ (C naphthalene), 131.63 (C naphthalene), 131.89 (C naphthalene), 132.34 (Cnaphthalene), 132.57 (Cnaphthalene), 132.90 (Cnaphthalene), 133.66 (Cnaphthalene), 136.12 (Cnaphthalene), 140.02 (Cnaphthalene), 147.45 (Cnaphthalene), $164.20(C=0), 166.35(C=0) . M S$ (ESI (+) positive ion mode [M+] $\mathrm{C}_{36} \mathrm{H}_{29} \mathrm{~N}_{3} \mathrm{O}_{2} \mathrm{~S}_{2}$ Found: 599,7644; Calculated: 600,2996. IR $(A T R) V_{\max }\left(\mathrm{cm}^{-1}\right)$ 2954, 2924, 2862, 1695 (C=O), 1656 (C=O), 1633, 1614, 1595, 1579, 
$1519,1456,1435,1394,1348,1315,1228,1257,1192,1118,1072,1029,972,781$, $761,717$.

3-(3,5-dimethyl-4-isoxazolyl)-N-butyl-4-bromo-1,8-naphthalimide(4)

N-butyl-3-iodo-4-bromo-1,8-naphthalimide (0.2 g, $0.43 \mathrm{mmol})$ (1), 3,5-dimethylisoxazole-4-boronic acid pinacol ester $(0.28 \mathrm{~g}, 1.29 \mathrm{mmol})(3)$, potassium carbonate $(0.59$ $\mathrm{g}, 4.3 \mathrm{mmol})$, tetrakis(triphenylphosphine)palladium(0) $(0.049 \mathrm{~g}, 0.043 \mathrm{mmol})$, and a catalytic quantity of tris(dibenzylideneacetone)dipalladium $(0)$ in tetrahydrofuran $(20 \mathrm{~mL})$ and water $(4 \mathrm{~mL})$ were stirred for $4 \mathrm{~h}$ at room temperature, and then this mixture was stirred for $2 \mathrm{~h}$ at $45-50{ }^{\circ} \mathrm{C}$. The mixture of solution was quenched with aqueous $\% 10$ $\mathrm{NaHCO}_{3}$ solution and extraction was carried out with ethyl acetate. The organic phase was washed with saturated $\mathrm{NaCl}$ solution, dried with anhydrous $\mathrm{MgSO}_{4}$ and the desiccant agent filtered. Then the solvent was evaporated on a rotary evaporator. Raw product was purified by column chromatography over silica gel with ethyl acetate/n-hexane. $\mathbf{4}$ yellow solid. Yield $0.014 \mathrm{~g}$ (76\%) m.p.:113-116 ${ }^{\circ} \mathrm{C} .{ }^{1} \mathrm{H}$ NMR (400 MHz, $\left.\mathrm{CDCl}_{3}, \mathrm{ppm}\right): \delta 0.90$ (t, 3H, $\left.\mathrm{CH}_{2} \mathbf{C H}_{3}\right), 1.30-1.42\left(\mathrm{~m}, 2 \mathrm{H},-\mathbf{C H}_{2} \mathrm{CH}_{3}\right), 1.59-1.71\left(\mathrm{~m}, 2 \mathrm{H},-\mathrm{NCH}_{2} \mathbf{C H}_{2}-\right), 2.11(\mathrm{~s}, 3 \mathrm{H},-$ $\mathrm{CH}_{3}$, isoxazole), $2.32\left(\mathrm{~s}, 3 \mathrm{H},-\mathrm{CH}_{3}\right.$, isoxazole), $4.09\left(\mathrm{t}, 2 \mathrm{H},-\mathrm{NCH}_{2}-\right), 7.84(\mathrm{t}, 1 \mathrm{H}$, naphthalene-H), $8.32(\mathrm{~s}, 1 \mathrm{H}$, naphthalene- $\mathrm{H}), 8.62\left(\mathrm{~d}, 2 \mathrm{H},{ }^{3} \mathrm{~J}_{\mathrm{H}-\mathrm{H}}=6.1 \mathrm{~Hz}\right.$, naphthalene- $\left.\mathrm{H}\right)$. ${ }^{13} \mathrm{C} \mathrm{NMR}(100 \mathrm{MHz}, \mathrm{CDCl} 3, \mathrm{ppm}): \delta=10.74\left(\mathrm{CH}_{3}\right), 11.91\left(\mathrm{CH}_{3}\right), 13.61\left(\mathrm{CH}_{3}\right), 20.40\left(\mathrm{CH}_{2}\right)$, $30.18\left(\mathrm{CH}_{2}\right), 40.50\left(\mathrm{CH}_{2}\right), 114.15$ (Cisoxazole), 121.72 (Cisoxazole), 123.20 (Cisoxazole), 128.40 (Cnaphthalene), 128.46 (Cnaphthalene), 128.53 (Cnaphthalene), 128.59 (Cnaphthalene), 128.65 (Cnaphthalene), 130.00 (C naphthalene), 131.11 (Cnaphthalene), 132.18 (Cnaphthalene), 133.28


mode $[\mathrm{M}+] \mathrm{C}_{21} \mathrm{H}_{19} \mathrm{BrN}_{2} \mathrm{O}_{3}$ Found: 426,0579; Calculated: 426,8548. IR (ATR) $\mathrm{V}_{\max }\left(\mathrm{cm}^{-1}\right)$ 2927, 2862, 1697 ( $C=0), 1649$ ( $C=0), 1600,1498,1431,1377,1342,1307,1261,1220$, $1155,1076,1045,972,854,821,785,665,632$.

\section{3,4-Bis(3,5-dimethyl-4-isoxazolyl)-N-butyl-1,8-naphthalimide(20)}

3-(3,5-dimethyl-4-isoxazolyl)-N-butyl-4-bromo-1,8-naphthalimide (4) (0.14 g， 0.32 $\mathrm{mmol}), 3,5$-dimethyl-isoxazole-4-boronic acid pinacol ester $(0.14 \mathrm{~g}, 0.65 \mathrm{mmol})(3)$, potassium carbonate $(0.44 \mathrm{~g}, 3.2 \mathrm{mmol})$, tetrakis (triphenylphosphine)palladium(0) $(0.036$ $\mathrm{g}, 0.032 \mathrm{mmol}$ ), and a catalytic quantity of tris(dibenzylideneacetone) dipalladium(0) in tetrahydrofuran $(20 \mathrm{~mL})$ and water $(4 \mathrm{~mL})$ were stirred for $2 \mathrm{~h}$ at $45-50{ }^{\circ} \mathrm{C}$, and then mixture of solution was boiled for $4 \mathrm{~h}$. The reaction was followed by TLC. Mixture of solution was quenched with aqueous $\% 10 \mathrm{NaHCO}_{3}$ solution and extracted with ethyl acetate. The organic phase was washed with saturated $\mathrm{NaCl}$ solution, dried with anhydrous $\mathrm{MgSO}_{4}$ and the desiccant agent filtered. Then the solvent was removed on a rotary evaporator. Raw product was purified by column chromatography over silica gel with ethyl acetate/hexane. 20 yellow solid. Yield $0.08 \mathrm{~g}(54 \%)$ m.p.: $128-130{ }^{\circ} \mathrm{C} .{ }^{1} \mathrm{H}$ NMR $\left(400 \mathrm{MHz}, \mathrm{CDCl}_{3}, \mathrm{ppm}\right): \delta$ 
$0.91\left(\mathrm{t}, 3 \mathrm{H},-\mathrm{CH}_{2} \mathbf{C H}_{3}\right), 1.32-1.40\left(\mathrm{~m}, 2 \mathrm{H},-\mathbf{C H}_{2} \mathrm{CH}_{3}\right), 1.60-1.68\left(\mathrm{~m}, 2 \mathrm{H},-\mathrm{NCH}_{2} \mathbf{C H}_{2}-\right), 2.19$ $\left(\mathrm{s}, 6 \mathrm{H},-\mathrm{CH}_{3}\right.$, isoxazole), $2.30\left(\mathrm{~s}, 3 \mathrm{H},-\mathrm{CH}_{3}\right.$, isoxazole $), 4.12\left(\mathrm{t}, 2 \mathrm{H},-\mathrm{NCH}_{2}-\right), 7.85(\mathrm{t}, 1 \mathrm{H}$, naphthalene-H), $8.33(\mathrm{~s}, 1 \mathrm{H}$, naphthalene- $\mathrm{H}), 8.63\left(\mathrm{~d}, 2 \mathrm{H},{ }^{3} \mathrm{~J}_{\mathrm{H}-\mathrm{H}}=6.2 \mathrm{~Hz}\right.$, naphthalene-H). ${ }^{13} \mathrm{C} \mathrm{NMR}\left(100 \mathrm{MHz}, \mathrm{CDCl}_{3}, \mathrm{ppm}\right): \delta=11.71\left(\mathrm{CH}_{3}\right), 11.91\left(\mathrm{CH}_{3}\right), 13.95\left(\mathrm{CH}_{3}\right), 20.27\left(\mathrm{CH}_{3}\right)$, $20.47\left(\mathrm{CH}_{3}\right), 24.96\left(\mathrm{CH}_{2}\right), 30.06\left(\mathrm{CH}_{2}\right), 40.46\left(\mathrm{CH}_{2}\right), 114.07$ (Cisoxazole), 114.27 ( $\left.\mathrm{C}_{\text {isoxazole }}\right)$, 121.62 (Cisoxazole), 121.82 (Cisoxazole), 123.25 (Cisoxazole), 128.34 (Cisoxazole), 128.55 (Cnaphthalene), 129.98 (Cnaphthalene), 131.00 (Cnaphthalene), 131.20 (Cnaphthalene), 132.02 (Cnaphthalene), 132.19 (C naphthalene), 132.22 (C naphthalene), 133.24 (Cnaphthalene), 138.95 (Cnaphthalene), 158.93 (Cnaphthalene), $163.57(\mathrm{C}=0), 166.98(\mathrm{C}=0)$ ). MS (ESI $(+)$ positive ion mode $\left[\mathrm{M}^{+}\right] \mathrm{C}_{26} \mathrm{H}_{25} \mathrm{~N}_{3} \mathrm{O}_{4}$ Found: 443.4944; Calculated: 444.1030. IR (ATR) $\mathrm{V}_{\max }\left(\mathrm{cm}^{-1}\right) 3084$, 3051, 2929, 2862, 1697 ( $C=0), 1647$ ( $C=0), 1589,1500,1435,1382,1348,1305,1261$, $1224,1161,1078,1043,1002,945,856,821,783,742,665,632$.

\section{RESULTS AND DISCUSSION}

The Suzuki cross-linking reaction is an organohalide with organoborane reaction to give the coupling product using a palladium catalyst and base. The result is a new C-C bond.

C-C bond formation reactions are crucial in the development of bioactive molecules as well as in the development of organic and inorganic materials with new electrical-electronic, mechanical and optical properties (28).

In this study, $\mathrm{N}$-butyl-3-iodo-4-bromo-1,8-naphthalimide and thiazole group containing arylboronic acid were prepared via a multi-stage reaction with method published by the author's group (11).

3,4-Bisaryl-N-butyl-1,8-naphthalimides were synthesized from the two-step Suzuki coupling reaction of $\mathrm{N}$-butyl-3-iodo-4-bromo-1,8-naphthalimide and arylboronic acid or pinacol ester of arylboronic acid in a medium yield (Figure 1).

10 was conveniently synthesized in moderate yield via one-step Suzuki coupling reaction between 1 equivalent of $\mathrm{N}$-butyl-3-iodo-4-bromo-1,8-naphthalimide $\mathbf{1}$ and average 3 equivalent of arylboronic acid $\mathbf{2}$. On similar terms, the reaction between N-butyl-3-iodo-4bromo-1,8-naphthalimide $\mathbf{1}$ and pinacol ester of arylboronic acid $\mathbf{3}$ to give compound $\mathbf{2 0}$ failed.

Instead, the intermediate product $\mathbf{4}$ was obtained as a yellow solid. Despite the fact that the one-step reaction was repeated with an extreme amount of arylboronic acid ester $\mathbf{3}$ as 
well as more effective reaction conditions, the desired product $\mathbf{2 0}$ was not isolated and some non-isolable by-products on TLC were observed. However, when the pure intermediate product $\mathbf{4}$ was treated with an extreme quantity of boronic acid ester $\mathbf{3}$, the expected product $\mathbf{2 0}$ was achieved in $54 \%$ yield as a yellow solid.

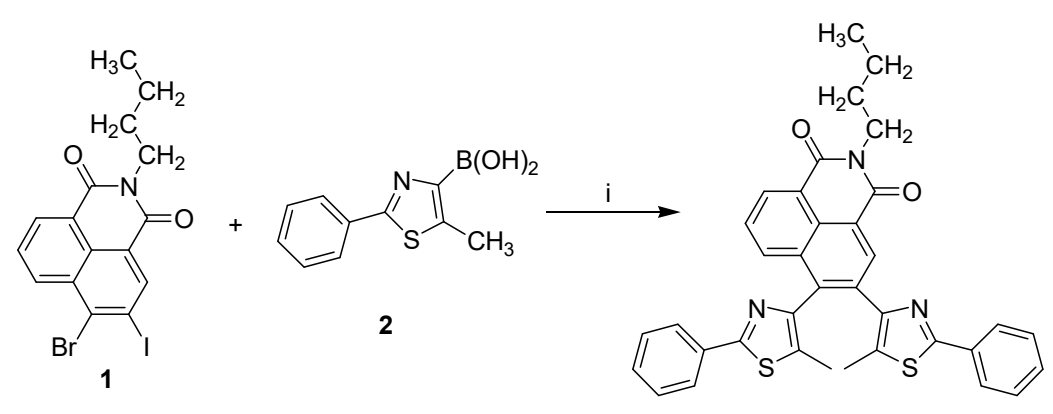

10

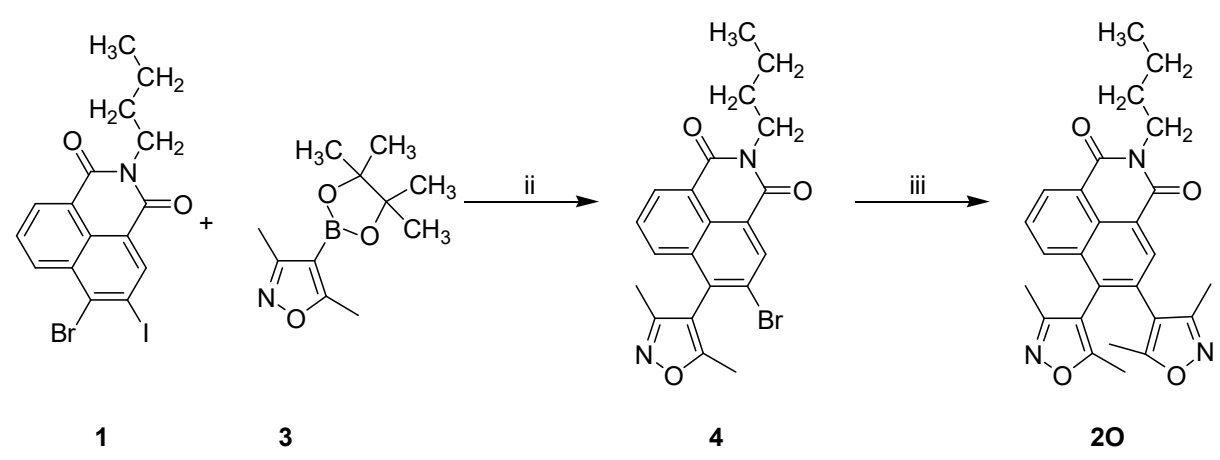

Figure 1. Synthesis of $\mathbf{1 0}$ and $\mathbf{2 0 .}$

Reaction conditions: i) $\mathrm{K}_{2} \mathrm{CO}_{3} / \mathrm{Pd}\left(\mathrm{PPh}_{3}\right)_{4}, \mathrm{H}_{2} \mathrm{O}$, THF, $60{ }^{\circ} \mathrm{C}$, 5h; ii) $\mathrm{K}_{2} \mathrm{CO}_{3} / \mathrm{Pd}\left(\mathrm{PPh}_{3}\right)_{4}, \mathrm{H}_{2} \mathrm{O}$, THF, r.t, 24 h; iii) Extreme reagent $3 / \mathrm{K}_{2} \mathrm{CO}_{3} / \mathrm{Pd}\left(\mathrm{PPh}_{3}\right)_{4}$, THF $60{ }^{\circ} \mathrm{C}, 5$ h.

Irradiation of thiazole group containing $\mathrm{N}$-butyl-1,8-naphthalimide $\mathbf{1 0}$ in ethyl acetate with $365 \mathrm{~nm}$ light caused a little yellow to blue-green color change, due to the formation of close form. The colored form (at pss) turned back to the first pale yellow solution of 10 upon exposure to visible light $(530 \mathrm{~nm})$. The close form with appropriate wavelength light and opening to the ring manifested itself as a common behavior of organic photochromic devices (Figure 2). Also, this compound $\mathbf{1 0}$ showed a good level fluorescence property.

Irradiation of $\mathbf{1 0}$ in ethyl acetate with $365 \mathrm{~nm}$ light caused a pale yellow to blue-green color change, because of the formation of 1C. The colored form 1C (at pss) turned back to the first light yellow solution of $\mathbf{1 0}$ upon exposure to visible light (Figure 4). 

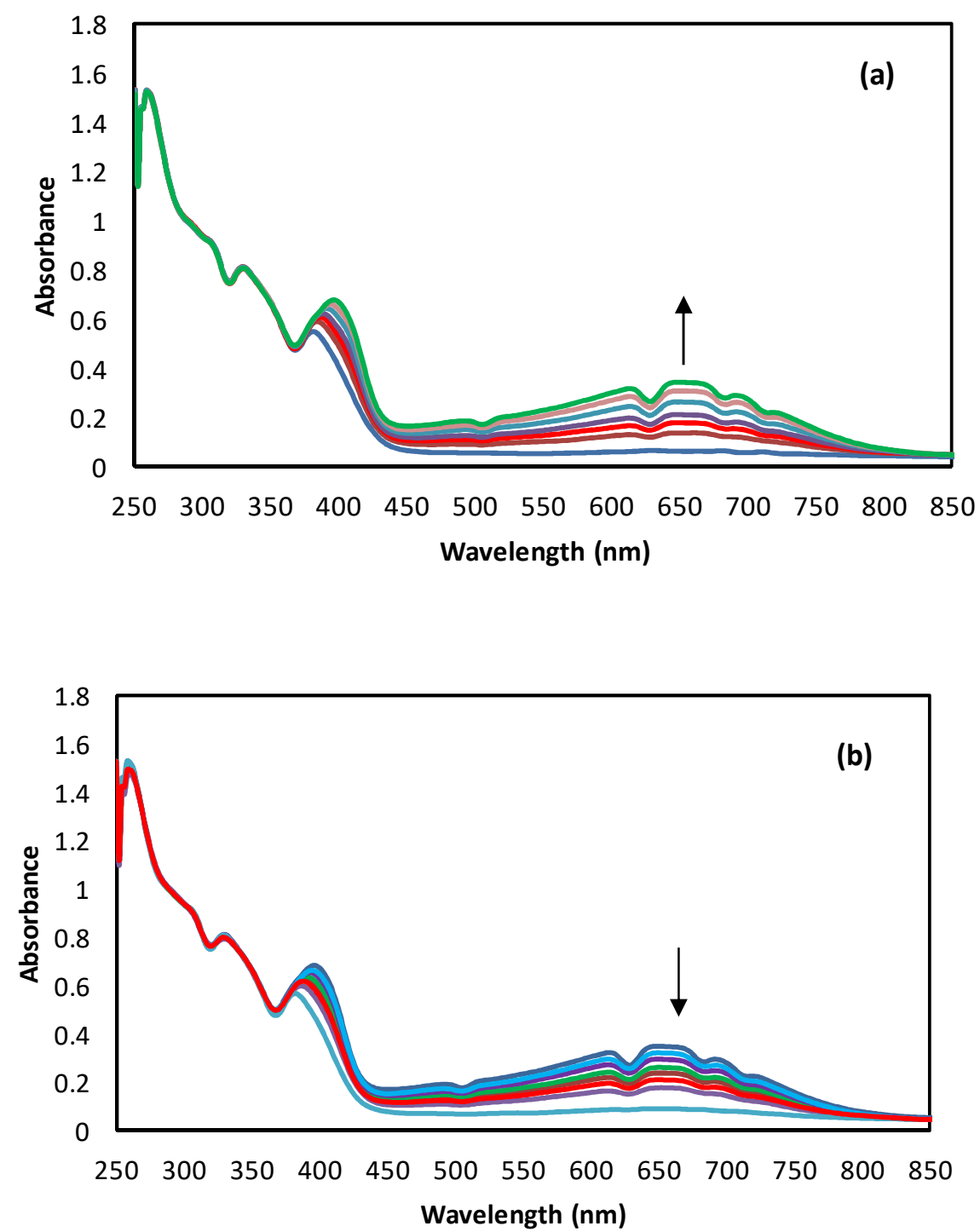

Figure 2. Absorption changes in acetonitrile $\left(1 \times 10^{-5} \mathrm{M}\right)$. (a) $\mathbf{1 0}$ to $\mathbf{1 C}$ (Ultraviolet-PSS). Irradiated with $365 \mathrm{~nm}$ ultraviolet light; (b) 1C (Ultraviolet-PSS) to 10. Irradiated with $530 \mathrm{~nm}$ visible light.

Other synthesized bis(3,5-dimethyl-4-isoxazolyl)-N-butyl-1,8-naphthalimide 20 was not photochromic. On the other hand, this prepared bis(3,5-dimethyl-4-isoxazolyl)-N-butyl1,8-naphthalimide 20 displayed certain amount of fluorescence properties.

During the irradiation with $365 \mathrm{~nm}$ light, neither a color nor a spectral change was seen. The reason why $\mathbf{2 0}$ does not show any photochromism is not certain clear at this step. However, this can be said by paying attention to the steric clogging of the methyl groups on carbon atom at 3 position on the isoxazoles with hydrogen atoms of naphthalimide moiety. If cyclic during photoreaction, the methyl group is thought to coincide with the 
hydrogen of the naphthalimide ring in Figure 3 . Although $\mathbf{2 0}$ is not a photochromic compound, $\mathbf{2 0}$ showed fluorescence. in Fig.

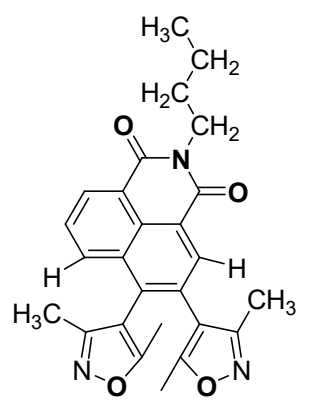

20

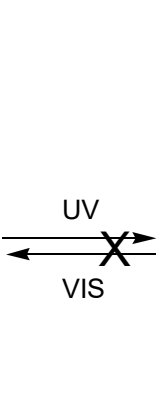

VIS



$2 \mathrm{C}$

Figure 3. Possible photoreaction of non-photochromic 20.

\section{Photochromism, Quantum yield, and conversion rate}

There was no absorption band in the visible range of $\mathbf{1 0}$ and the solutions seen colorless. Upon irradiation with Ultraviolet light, the solution 10 turned greenish with an increase in novel peaks in the visible region. This shows an extended $\pi$ system on the photochromic reaction, as shown in Figure 4.

Forward and backward photoreaction of 3,4-bisaryl-N-butyl-1,8-naphthalimides in solutions was carried out with different light wavelengths. Upon irradiation of $\mathbf{1 0}$ and $\mathbf{2 0}$ in solutions with ultraviolet light (365 nm), the color changes from near colorless to bluegreen was appeared due to the formation of their closed form $\mathbf{C}$-form, which turned back to the colorless states upon exposure to visible light $(530 \mathrm{~nm})$. Figure 4 shows the photochromic structure changes of 3,4-bis(2-phenyl-5-methyl-4-thiazolyl)-N-butyl-1,8naphthalimide 10. The absorption spectral variations of $\mathbf{1 0}$ to its photostationary state (pss) incorporating 1C in acetonitrile upon ultraviolet and visible beam irradiation are shown in Figure 2.

Ultraviolet-visible absorptivity and extinction coefficients of open-form $\mathbf{1 0}$ and this ring closure form 1C are summarized in Table 1 before and after irradiation in different solvents. Generally, for photochromic compound 10, the two thiazolyl groups are not in the same plane due to their steric congestion, but are every time in parallel and antiparallel form. Whereby the observed characteristic absorption peaks of the naphthalimide units indicate poor conjugation between the open thiazolyl groups and the naphthalimide moiety. 


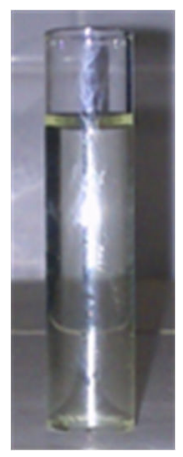

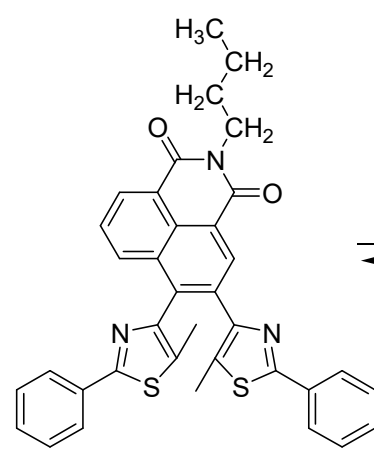

10

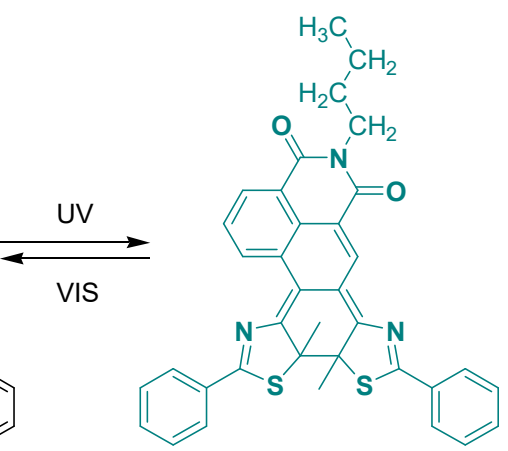

$1 \mathrm{C}$

blue-green

$\lambda \max =658 \mathrm{~nm}$

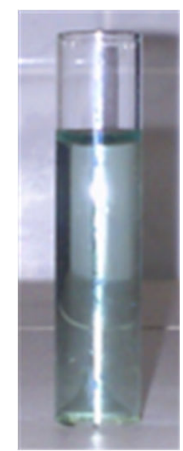

Figure 4. Photochromic structure changes of 10.

The colored blue-green photochromic compound $\mathbf{1 C}$ has maximum absorption approximately at $750 \mathrm{~nm}$ with an absorption trough to the near infrared region. The diode in $780<\lambda<840 \mathrm{~nm}$ region can react to laser radiation. It is essential for these optical memory devices.

Solvent effects on the open-form $\mathbf{1 0}$ and its closure isomer 1C were studied in four various solvents and the data are given in Table 1 . The polarity of the solvent showed a bathochromic shift in both colored and uncolored forms. The quantum efficiency of coloring $(\varphi c)$ at $365 \mathrm{~nm}$ and open-form 10 bleaching $(\varphi b)$ at $530 \mathrm{~nm}$ of its colored form $\mathbf{1 C}$ were calculated with reference to the chemical actinometer Aberchrome 540 as developed by Heller (27).

Table 1. Ultraviolet-Visible maximum absorption and extinction coefficients of open-form

$\mathbf{1 0}$ and its closed isomer $\mathbf{1 C}$ in several solvents.

\begin{tabular}{|l|l|l|l|l|}
\hline Solvent & \multicolumn{2}{|c|}{ O-Form (10) } & \multicolumn{2}{c|}{ C-Form (1C) } \\
\hline Hexane & $\lambda_{\max }(\mathrm{nm})$ & $\varepsilon_{\max }\left(\mathrm{mol}^{-1} \mathrm{dm}^{3} \mathrm{~cm}^{-1}\right)$ & $\lambda_{\max }(\mathrm{nm})$ & Absorbance (at Pss) \\
\hline Toluene & 328 & 36800 & 651 & 0.276 \\
\hline Ethyl acetate & 336 & 37500 & 657 & 0.266 \\
\hline Acetonitrile & 361 & 29900 & 658 & 0.283 \\
\hline
\end{tabular}

The quantum yields of the ring closure isomer $(\Phi O \rightarrow C)$ of 0 -form 10 with $365 \mathrm{~nm}$ beam irradiation and the ring open isomer $(\Phi C \rightarrow O)$ of $\mathbf{1 C}$ form with $530 \mathrm{~nm}$ beam irradiation were calculated with reference to Langan R. and Heller HG. Aberchrome 540[27]. The quantum efficiency for coloring $(\varphi c)$ and bleaching $(\varphi b)$ were calculated to be $\Phi O \rightarrow C=$ 0.44 and $\Phi C \rightarrow O=0.09$. Reference the actinometer is known as $\Phi O \rightarrow C=0.20$ at $366 \mathrm{~nm}$ 
and $\Phi C \rightarrow O=0.044 .69 \%$ at $546 \mathrm{~nm}$ in toluene. The quantum yield of $\mathbf{1 0}$ and $\mathbf{1 C}$ are quite good from the reference compound.

HPLC followed the closed form of the photocyclization. The conversion ratio from $\mathbf{1 0}$ to $\mathbf{1 C}$ (at the pss) of $365 \mathrm{~nm}$ light irradiation was detected by HPLC and was calculated to be $71 \%$. Conversion rate was found by calculation of HPLC peak areas. The HPLC chromatogram of 10, before and after irradiation (365 nm) to pss are given in Figure 5 .
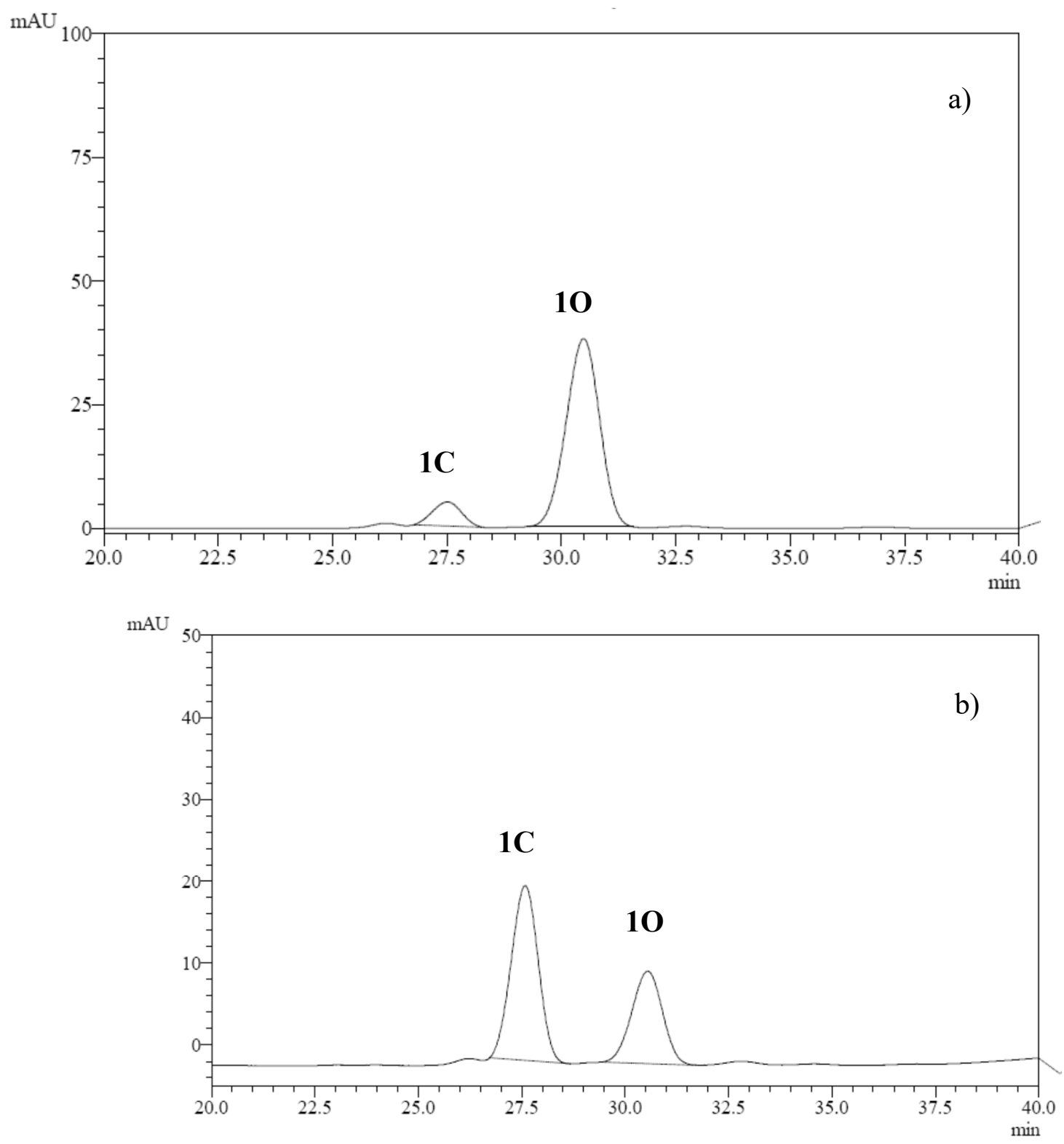

Figure 5. HPLC chromatogram of 10. a) Before $365 \mathrm{~nm}$ irradiation; b)After $365 \mathrm{~nm}$ irradiation to pss. HPLC conditions: Column (C8-3); Eluent: $\mathrm{H}_{2} \mathrm{O} / \mathrm{CH}_{3} \mathrm{CN}(50 \% / 50 \%, \mathrm{v} / \mathrm{v})$; Current: $0.7 \mathrm{~mL} /$ minute; Injection: $20 \mu \mathrm{L}$; detection wavelength:320 nm (isobestic point in $\mathrm{CH}_{3} \mathrm{CN}$ ). 


\section{Fluorescent behavior}

Photochromic compounds can potentially be applied in the recording medium, where the two states can be read with properties prepared by photochromic reactions such as electrochemical states, fluorescence, and absorbance. Fluorescence emission between these outputs is considered one of the interesting due to the simply of detection. The naphthalimide unit as the fluorophore was included in the direct centering bridge for the fluorescence unit target. Upon irradiation at $365 \mathrm{~nm}$, the polar and nonpolar solution of 10 showed a fluorescence quenching, a significant fluorescence quenching that markedly decreased when it reached the photodenase state in Figure 6 . The reason for this is the closed form isomer as a fluorescence extinguisher in the possible resonance energy transfer channel.

2-phenylthiazole group with naphthalimide exhibits a fluorescence photo-transfer property. By irradiation with $350 \mathrm{~nm}$ light, open structure isomer $\mathbf{1 0}$ showed maximum fluorescence emission at $460 \mathrm{~nm}$, but closed structure isomer 1C showed lower intensity fluorescence in Figure 6.
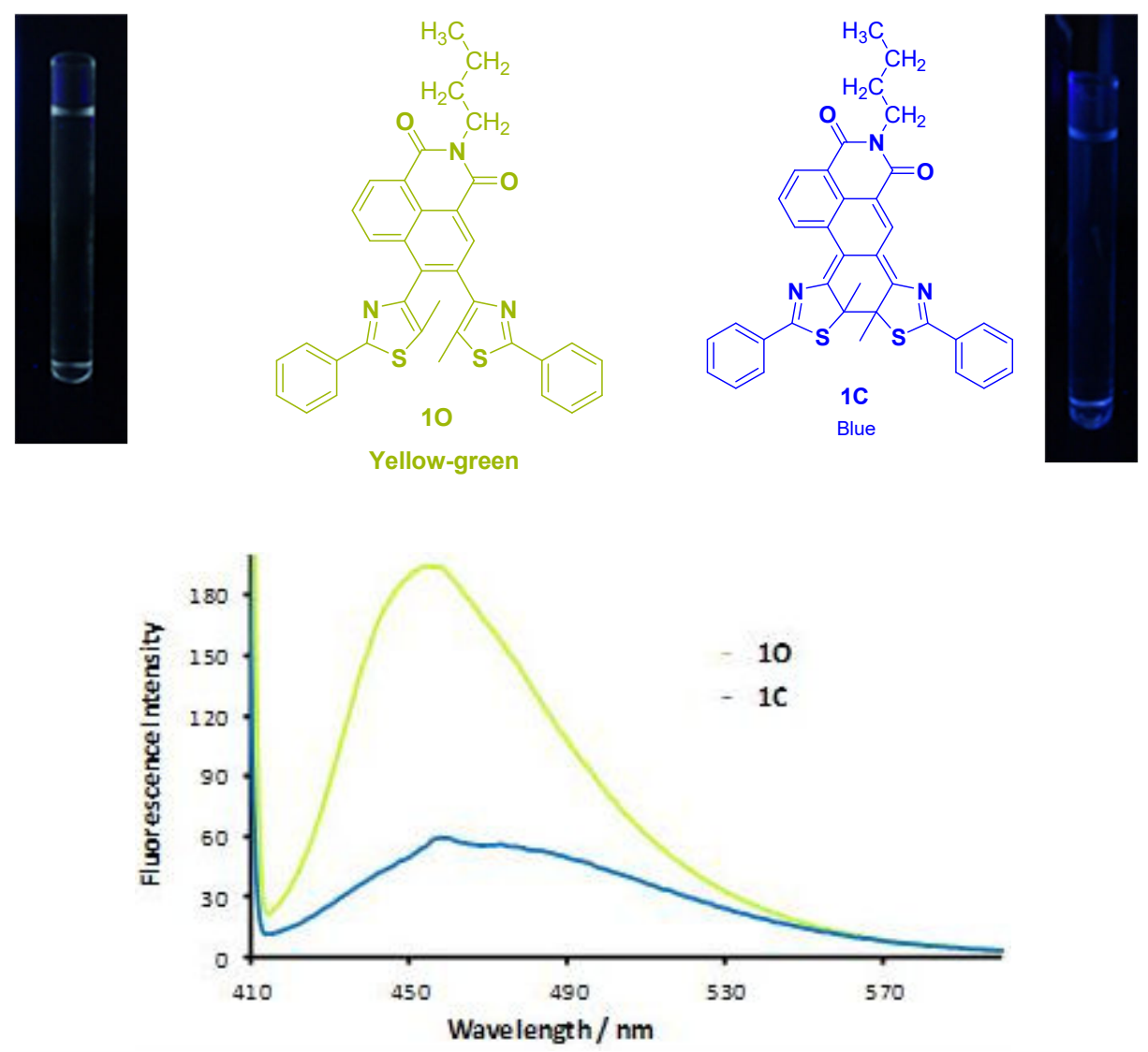

Figure 6. Fluorescence intensity spectra of $\mathbf{1 0}$ and $\mathbf{1 C}$ before and after upon irradiation with UV light in ethyl acetate $\left(1 \times 10^{-5} \mathrm{M}\right)$. 
Similarly, the open form $\mathbf{2 0}$ compound containing the isoxazole group gave fluorescence intensity at longer wavelengths in the polar solvent (Figure 7).

Compound 20 gave an emission intensity around $460 \mathrm{~nm}$ in the non-polar hexane solution. Compound 20 showed an emission intensity around $520 \mathrm{~nm}$ in polar acetone in Figure 7. In the polar solvent, a longer wavelength of fluorescence intensity was seen.

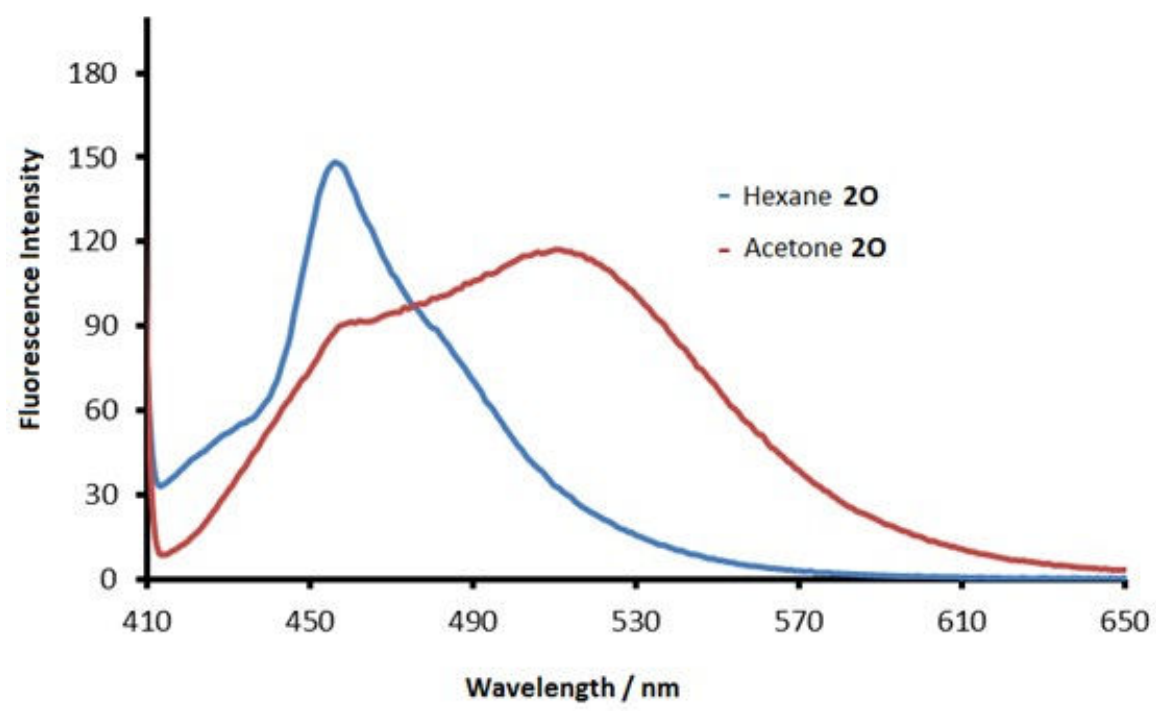

Figure 7. Fluorescence emission spectral changes of compound $\mathbf{2 0}$ in hexane and acetone $\left(1 \times 10^{-5}\right),\left(\lambda_{\text {ex }} 380 \mathrm{~nm}\right)$.

We can say that solvent polarity is an important factor in the red shift between nonpolar hexane and polar acetonitrile at the luminescence wavelength of $\mathbf{1 0}$. In general, as the solvent polarity increases, the emission intensity shifts to a longer wavelength.

The fluorescence color of $\mathbf{1 0}$ can be well modulated by adjusting the solvent polarity ratio with $20 \%$ increase in the acetone volume ratio of $0-100 \%$, which can be seen directly by the naked eye in Figure 8. 


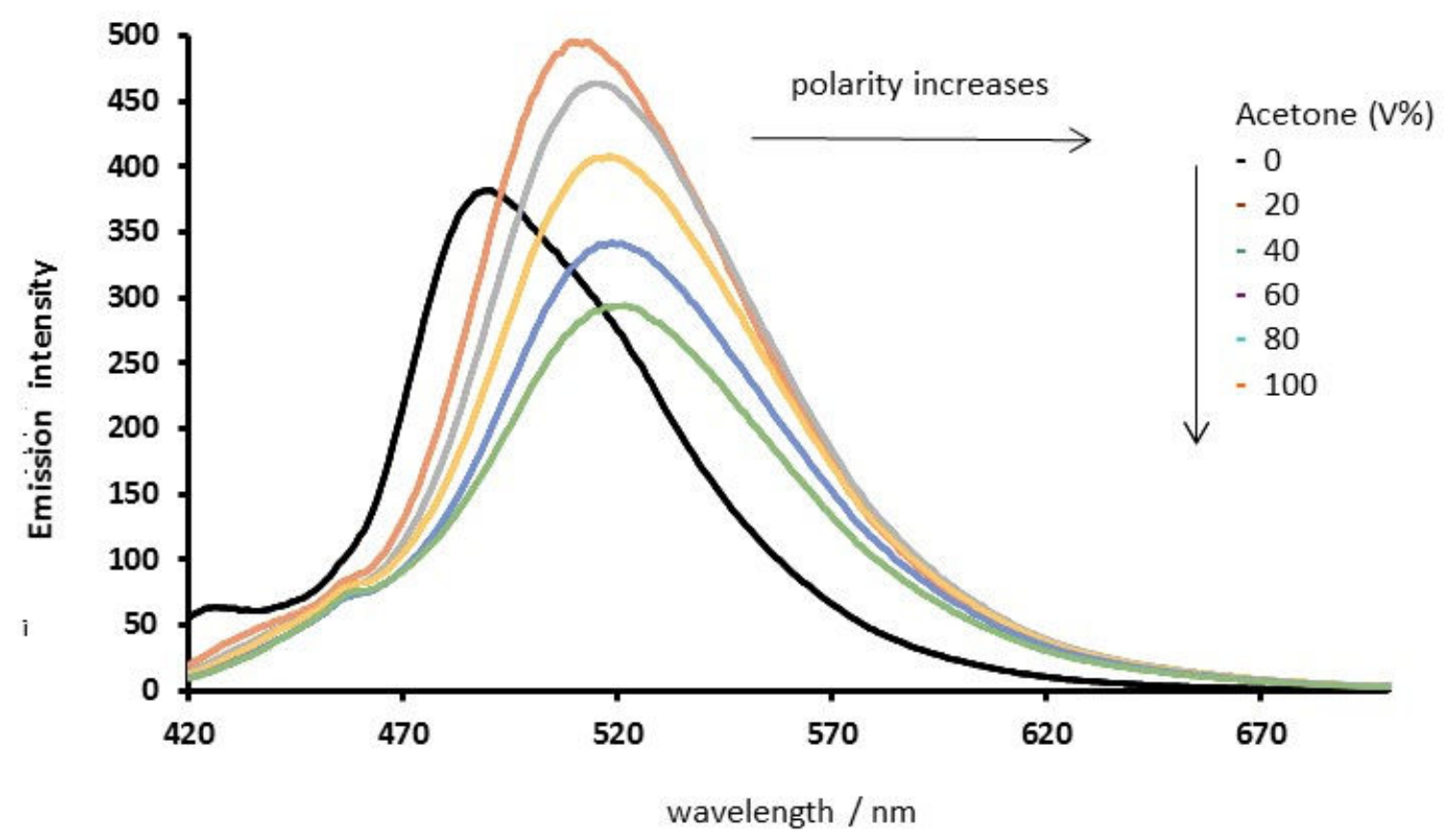

Figure 8. Solvent effect on the fluorescence of $\mathbf{1 0}$ with an increase of acetone proportion in $\mathbf{n -}$ hexane.

\section{CONCLUSIONS}

Starting compound "N-butyl-4-bromo-3-iodo-1,8-naphthalimide" was prepared from 4bromo-1,8-naphthalic anhydride with multiple-step reactions. Bisaryl naphthalimide derivatives were synthesized from the Suzuki coupling reaction of N-butyl-3-iodo-4-bromo1,8-naphthalimide and hetereoaryl boronic acid or hetereoaryl boronic acid pinacol ester. From N-butyl-3-iodo-4-bromo-1,8-naphthalimide symmetrical isoxazole and thiazole group containing N-butyl-1,8-naphthalimides were prepared by Suzuki coupling reaction. Among them, only thiazole group containing $\mathrm{N}$-butyl-1,8-naphthalimides 10 displayed photochromism. Detailed photochromic and fluorescence property of $\mathbf{1 0}$ and 1C was investigated. As well as the fluorescence behavior of $\mathbf{2 0}$.

Solvent factor on the fluorescence properties of $\mathbf{1 0}$ and $\mathbf{2 0}$ was studied. Increase of solvent polarity results in a red shift (to longer wavelengths) of the fluorescence emissions. Conversion ratios were also calculated from HPLC chromatograms.

\section{ACKNOWLEDGEMENTS}

The author thanks to TUBİTAK (Scientific and Technical Research Council of Turkey) (Grant No.: 111T490) and Duzce University Research Fund (Grant No.: BAP-2012.05.03.097) for the financial contribution of this work. 


\section{REFERENCES}

1. Tsujioka T, Irie M. Electrical functions of photochromic molecules. Journal of Photochemistry and Photobiology C: Photochemistry Reviews. 2010 Mar;11(1):1-14.

2. Rau H, Durr H. Photochromism: molecules and systems. Photochromism, Molecules and Systems. 1990;165-192.

3. Irie M. Diarylethenes for Memories and Switches. Chemical Reviews. 2000 May;100(5):1685716.

4. Köse M, Orhan E. Comparison of photochromic properties and thermal stabilities of fulgide, fulgimide, and benzimidazole[1,2-a]pyrrolidine-2-one derivatives. Turk J Chem. 2009;33:579-88.

5. Kose M, Orhan E, Büyükgüngör O. Synthesis of novel photochromic methyl cyanoacetatecondensed fulgide derivatives. Journal of Photochemistry and Photobiology A: Chemistry. 2007 May; $188(2-3): 358-63$.

6. Kose M, Orhan E. Studies on photochromic benzimidazol[1,2a]pyrrolidin-2-ones from the condensation of 2-methyl-3-benzothienylethylidene-(isopropylidene)succinic anhydride with 1,2diaminobenzenes. Journal of Photochemistry and Photobiology A: Chemistry. 2006 Jan;177(23):170-6.

7. Matsuda K, Irie M. Diarylethene as a photoswitching unit. Journal of Photochemistry and Photobiology C: Photochemistry Reviews. 2004 Oct;5(2):169-82.

8. Krayushkin M, Ivanov S, Martynkin AY, Lichitsky B, Dudinov A, Uzhinov B. Photochromic dihetarylethenes. 7. Synthesis of bis (thienylazoles), photochromic analogs of diarylethenes. Russian Chemical Bulletin. 2001;50(1):116-121.

9. Nakashima T, Atsumi K, Kawai S, Nakagawa T, Hasegawa Y, Kawai T. Photochromism of Thiazole-Containing Triangle Terarylenes. European Journal of Organic Chemistry. 2007 Jul;2007(19):3212-8.

10. Orhan E, Gundogdu L, Kose M, Yokoyama Y. Synthesis and photochromic properties of 4,5bisaryl-3(2H)-pyridazinones. Journal of Photochemistry and Photobiology A: Chemistry. 2016 Jan;314:164-70.

11. Meng X, Zhu W, Zhang Q, Feng Y, Tan W, Tian H. Novel Bisthienylethenes Containing Naphthalimide as the Center Ethene Bridge: Photochromism and Solvatochromism for Combined NOR and INHIBIT Logic Gates. The Journal of Physical Chemistry B. 2008 Dec 11;112(49):1563645.

12. Tian $\mathrm{H}$, Wang S. Photochromic bisthienylethene as multi-function switches. Chem Commun. 2007;(8):781-92.

13. Kanazawa R, Nakashima T, Kawai T. Photophysical Properties of a Terarylene Photoswitch with a Donor-Acceptor Conjugated Bridging Unit. The Journal of Physical Chemistry A. 2017 Mar $2 ; 121(8): 1638-46$.

14. Cheng H-B, Tan X, Pang M-L. Near-Infrared Photochromic Diarylethenes Based on the Changes in the $\Pi$-Conjugated System and the Electronic Properties of the Heteroaryl Moieties: Near-IR Photochromic Diarylethenes. European Journal of Organic Chemistry. 2013 Dec;2013(35):793340.

15. Nakashima T, Goto M, Kawai S, Kawai T. Photomodulation of Ionic Interaction and Reactivity: Reversible Photoconversion between Imidazolium and Imidazolinium. Journal of the American Chemical Society. 2008 Nov 5;130(44):14570-5.

16. Liu H-H, Chen Y. Modulation of absorption and fluorescence of photochromic diarylethene by intramolecular hydrogen bond. Journal of Physical Organic Chemistry. 2012 Feb;25(2):142-6. 
17. Lin Q, Xiao S, Li R, Tan R, Wang S, Zhang R. Intermolecular hydrogen bonding-assisted high contrast fluorescent switch in the solid state. Dyes and Pigments. 2015 Mar;114:33-9.

18. Fukaminato T. Single-molecule fluorescence photoswitching: Design and synthesis of photoswitchable fluorescent molecules. Journal of Photochemistry and Photobiology C: Photochemistry Reviews. 2011 Nov;12(3):177-208.

19. Jiang G, Wang S, Yuan W, Zhao Z, Duan A, Xu C, et al. Photo- and Proton-Dual-Responsive Fluorescence Switch Based on a Bisthienylethene-Bridged Naphthalimide Dimer and Its Application in Security Data Storage. European Journal of Organic Chemistry. 2007 May;2007(13):2064-7.

20. Kose M, Orhan E, Suzuki K, Tutar A, Ünlü CS, Yokoyama Y. Preparation and photochromic properties of 2,3-bisarylbenz[f]indenones. Journal of Photochemistry and Photobiology A: Chemistry. 2013 Apr;257:50-3.

21. Berberich M, Natali M, Spenst $P$, Chiorboli C, Scandola F, Würthner F. Nondestructive Photoluminescence Read-Out by Intramolecular Electron Transfer in a Perylene BisimideDiarylethene Dyad. Chemistry - A European Journal. 2012 Oct 22;18(43):13651-64.

22. Pu S, Li H, Liu G, Liu W, Cui S, Fan C. Synthesis and the effects of substitution upon photochromic diarylethenes bearing an isoxazole moiety. Tetrahedron. 2011 Feb;67(7):1438-47.

23. Kawai S, Nakashima T, Kutsunugi Y, Nakagawa $H$, Nakano H, Kawai T. Photochromic amorphous molecular materials based on dibenzothienylthiazole structure. Journal of Materials Chemistry. 2009;19(22):3606-3611.

24. Shirinian VZ, Lonshakov DV, Kachala VV, Zavarzin IV, Shimkin AA, Lvov AG, et al. Regio- and Chemoselective Bromination of 2,3-Diarylcyclopent-2-en-1-ones. The Journal of Organic Chemistry. 2012 Sep $21 ; 77(18): 8112-23$.

25. Morinaka K, Ubukata T, Yokoyama Y. Structurally Versatile Novel Photochromic Bisarylindenone and Its Acetal: Achievement of Large Cyclization Quantum Yield. Organic Letters. 2009 Sep $3 ; 11(17): 3890-3$.

26. Kose M, Şekerci ÇY, Suzuki K, Yokoyama Y. Synthesis of photochromic 2,3-bis(5-methyl-2phenyl-4-thiazolyl)-1,4-naphthoquinone derivatives. Journal of Photochemistry and Photobiology A: Chemistry. 2011 Mar;219(1):58-61.

27. Heller HG, Langan JR. Photochromic heterocyclic fulgides. Part 3. The use of (E)-a-(2,5dimethyl-3-furylethylidene)(isopropylidene)succinic anhydride as a simple convenient chemical actinometer. J Chem Soc, Perkin Trans 2. 1981;(2):341-3.

28. Miyaura N, Yamada K, Suzuki A. A new stereospecific cross-coupling by the palladiumcatalyzed reaction of 1 -alkenylboranes with 1 -alkenyl or 1-alkynyl halides. Tetrahedron Letters. 1979 Jan;20(36):3437-40. 